JURNAL PARIWISATA BUDAYA, VOLUME 3, NOMER 2 TAHUN 2018

HALAMAN 34-41

\title{
Peran Masyarakat dalam PKB bagi Pariwisata yang Berkelanjutan
}

\author{
Amirosa Ria Satiadji \\ amirosaria@gmail.com \\ $+628123816747$ \\ Sekolah Tinggi Pariwisata Bali
}

\begin{abstract}
Cultural preservation is a very important thing to do so that the existence of a culture in the community will still be hereditary. All parties should contribute to the preservation of the culture. Moreover, Bali is a culture-based tourist destination in its development. So that culture is typical of Bali where tourists visiting Bali really admire it. One of the events best known by Balinese people is the Bali Arts Festival. The Bali Arts Festival is a cultural event organized by the Provincial Government of Bali with the Bali Provincial Culture Office as the executor. In this study, we want to know whether the role of society in cultural preservation is carried out through an event called the Bali Arts Festival. The research method used is a qualitative method with data collection techniques in the form of interviews and simple quantitative questionnaires distributed to foreign tourists. The results obtained from this study are as follows: The role as an artist, audience, marketer for the Bali Arts Festival event, as parents who support and direct their children, as well as the role of children who love their mothers so that it can take place hereditary.

Keywords: tourism, culture, sustainable, marketing, event.
\end{abstract}

\section{Pendahuluan}

Dalam masyarakat Bali, peran Jero Bendesa Adat sebagai pemimpin tertinggi dalam desa adat memegang peranan yang besar. Jero Bendesa Adat memimpin desa pekraman dengan satu atau beberapa kelian adat tergantung kepada jumlah banjar adat yang dimiliki sebagai wilayahnya. Di dalam pelestarian budaya, peran desa adat dan desa dinas saling terkait. Desa adat yang dipimpin oleh Jero Bendesa Adat dan desa dinas yang dipimpin lurah selalu berkoordinasi untuk membangun sinergitas. Warga dari desa adat disebut Krama/Krama sedangkan warga dari Desa Dinas disebut masyarakat. Krama banjar yang merupakan masyarakat dalam melakukan kegiatan di 
dalam sekaa atau sanggar di dalam wilayah suatu banjar harus selalu atas sepengetahuan Kelian Banjar, dan dilakukan koordinasi dengan desa adat dan desa dinas demikian sebaliknya dari atas kebawah koordinasi selalu dibangun sehingga terbangun sinkronisasi langkah pelestarian budaya yang dilakukan.

Semua jenis kebudayaan yang dimiliki di masyarakat haruslah dilestarikan sepanjang kebudayaan tersebut baik, dalam artian sesuai dengan ajaran Agama Hindu. Namun terdapat pula kebiasaan yang harus dihilangkan sehingga tidak mencemarkan budaya tersebut, seperti dalam mengkonsumsi miras (minuman keras) yang dalam bahasa Bali adalah arak secara berlebihan sehingga mabuk. Budaya yang jelek tersebut sepatutnya disirnakan dengan membangun penyadaran bagi generasi muda akan ajaran Agama Hindu. Terdapat pula budaya yang harus direvitalisasi, digali, dan dikembangkan sesuai dengan kreatifitas, imajinasi, dan inovasi dari para seniman Bali.

Desa Adat juga sangat berperan dalam pariwisatabudaya di Bali, dimanakreatifitas budaya dalam masyarakatnya Roh-nya adalah Agama Hindu. Dalam ajaran Agama Hindu terdapat Tiga Kerangka Dasar yaitu: Tatwa, Susila, dan Upacara yang diaplikasikan dalam ritual, etika, dan upacara persembahyangan. Sepanjang ajaran Agama Hindu tetap dijalankan oleh masyarakatnya, maka pariwisata budaya di Bali akan tetap bisa dilanjutkan. Masyarakat Hindu sangat kental dengan konsep "Ngayah" berkorban tanpa menuntut imbalan (menyumbangkan kreatifitasnya) untuk melakukan kegiatan kepada Tuhan (Niskala) yang disebut Ida Sang Hyang Widhi Wasa. Masyarakat bersedia untuk bergotong royong bekerja di desa dan Pura untuk membangun sesuatu demi kepentingan bersama, berkesenian seperti menabuh dan menari untuk tujuan keagamaan yang sesungguhnya merupakan tujuan utama dalam berkesenian. Bagi penganut Agama Hindu, adalah suatu kewajiban untuk dapat menarikan tari Rejang bagi laki-laki dan tari Pendet bagi perempuan untuk tujuan ritual keagamaan. Pada awalnya masyarakat belajar untuk tujuan keagamaan, kemudian setelah bisa akan berkembang untuk terus mempelajari seni, sampai pada akhirnya memberikan dampak secara kapital dalam perekonomiannya.

Sebuah event yang telah dilaksanakan berturut-turut setiap tahunnya dengan melibatkan seluruh kabupaten dan kota di Bali sejak tahun 1979 adalah Pesta Kesenian Bali. Sebuah event budaya yang sangat spektakuler ini dilaksanakan oleh pemerintah Provinsi Bali yang melibatkan segenap elemen masyarakat diharapkan dapat terus menjaga kelestarian budaya Bali dengan berbagai tujuan lainnya.

Winter (dalam Preston, 2012: 7) mengatakan bahwa event adalah suatu aspek yang integral dalam marketing mix:

"Event creation and production is a critical element to an overall marketing and communication program. Years ago marketing was very such segmented by channel. You either required advertising, public relation, or promotion as channel to reach the customer, but as the industries converged through the years, so too did the individual elements. As the result, events are as important a part of the process as is the art publicizing and promoting what those events are designed to do." 
(Kotler\&Keller. 2009: 64) menjelaskan mengenai internal marketing sebagai berikut: "Internal marketing is the task of hiring, training, and motivating able employees who want to serve customers well. Smart marketers recognize that marketing activities within the company can be as important as or even more important than marketing activities directed outside the company. It makes nosensetopromise excellent service before the company's staffis ready to provideit.... Internal marketing thus requires vertical alignment with senior manage mentand horizontal alignment with other departments, so every one understands, appreciates, and supports the marketing efforts."

Menurut Kotler (2002: 338-341) pemasaraninternal adalah pemasaran yang diarahkan ke dalam, yaitu kepada karyawan perusahaan. Pemasaran internal adalah proses yang mencakup langkah-langkah berikut:

1. Pembentukan budaya pelayanan

2. Pengembangan pendekatan pemasaran terhadap manajemen sumber daya manusia

3. Penyebaran informasi pemasaran kepada karyawan

4. Penerapan sistem imbalan dan pengakuan.

Dari keempathaltersebutmenunjukkanpemasaran yang dilakukan ke dalam, yaitu kepada para karyawan untuk memperkuat sisi dalam perusahaan.

"The creationofgoodwill, understanding, cooperation, andsharedvisionwithin a corporationisgenerallyreferredto as internal marketing, and has long utilizedplannedevents as a meansofachievingtheseends" (Preston, 2012: 167).

Salah satu program yang dapat berfungsi untuk memahami budaya pelayanan dalam perusahaan sebagai salah satu tujuan pemasaran internal adalah melalui event.Kotler et.al (dalam Kartajaya, 2010: 90) menjelaskan bahwa

"metode marketing saat ini menekankan pada nilai-nilai kemanusiaan. Terkait dengan hal ini, banyak hal buruk yang mungkin terjadi apabila perusahaan tidak mengaplikasikan sharedvalue yang dimiliki. Salah satunya dengan menjadi buruknya citra perusahaan dan bisnis. Banyak konsumen yang tidak lagi percaya pada perusahaan dan eksekutif perusahaan."

\section{Pembahasan}

Dalam kaitannya dengan PKB, setelah bisa berkesenian, masyarakat akan berkembang untuk mempelajari, lalu "Ngayah" kepada Pemerintah untuk dapat tampil dalam PKB, dan diberikan Kapital sebagai benefit yang didapatkan. Disebut "Ngayah" karena sesungguhnya nominal yang didapatkan oleh personil tim yang tampil, penyusun naskah, dan penggarap dalam PKB tersebut sesungguhnya tidaklah besar karena adanya kebutuhan lain seperti biaya kostum, kendaraan, dan konsumsi. Namun dengan adanya konsep "Ngayah" bagi para masyarakat yang merupakan seniman, untuk dapat tampil dalam PKB adalah merupakan suatu kebanggaan yang merupakan suatu penghargaan bagi diri seniman tersebut.

I Made Wedana, Kabid Adat Dinas Kebudayaan Kota Denpasar, mengharapkan dalam pemasaran Pariwisata Budaya yang dilakukan haruslah tetap mengacu pada koridor, batasan persyaratan, dan aturan Agama Hindu. Apa yang dipasarkan juga haruslah 
sesuai. Pemasar diharapkan mampu membedakan apa yang boleh dan tidak boleh dilakukan. Seperti pertunjukkan kesenian sakral ditempat yang tidak seharusnya, tidaklah boleh dilakukan. Kesenian sakral boleh dijadikan suatu atraksi bagi wisatawan sepanjang tujuan dari seni sakral tersebut adalah untuk tujuan ritual keagamaan. Wisatawan boleh menonton kesenian tersebut, namun pada wilayah yang ditentukan, dengan pakaian yang seharusnya (tata cara berpakaian), serta mentaati aturan yang ada (seperti wanita tidak boleh menonton atau masuk areal Pura ketika sedang menstruasi). Disinilah peran Desa Adat sangat penting terlibat, seperti dengan adanya Pecalang. Hal-hal tersebut seharusnya dipahami benar oleh pelaku pariwisata yang menjalankan pariwisata budaya di Bali. Sebagai contok pelaku pariwisata yaitu pemandu wisata. Pemandu wisata haruslah paham mengenai semua aturan Agama Hindu yang berlaku di Bali, sehingga perlu adanya pemahaman seperti dengan diberikannya bimbingan yang benar secara berkala. Diharapkan dalammemasarkan pariwisata budaya, para pemangku kepentingan janganlah kapitalis hanya memandang nilai ekonomi yang ada, namun sesuai dengan norma-norma aturan yang berlaku.

Diharapkan di dalam menjalankan pariwisata budaya, budaya merupakan paham yang harus dipegang. Dengan budaya, pelaku pariwisata, masyarakat, dan siapapun yang terlibat akan menjadi santun sepanjang budaya tersebut dimengerti, dihayati, dipahami, serta dilaksanakan sebagai implementasi dalam bentuk tindakan dan karya. Maka seharusnya di dalam melaksanakannya haruslah kembali kepada Ajaran Agama yang benar, Agama apapun yang dipercayai oleh pelaku pariwisata sehingga dapat berjalan sesuai dengan budaya yang santun. Diharapkan dari Konsep Agama Hindu Tri Kaya Parisuda dapat menjadi konsep manajemen modern, yaitu dengan pikiran yang benar, pembicaraan yang benar, serta tingkah laku yang benar dengan vibrasi yang berwawasan budaya segala sesuatu dapat berjalan baik seperti pariwisata budaya yang berjalan di Bali.

\section{Peran Masyarakat}

Setelah mendapatbantuankeuangandaripemerintahProvinsi Bali, Sekaa, Sanggar, ataupunorganisasikemasyarakatanlainnyabertugas:

a. Melaksanakanpementasankesenianpada PKB sesuaidenganpetunjukteknis

b. Menggunakan dana bantuansesuaipetunjukteknis

c. Mempertanggungjawabkanpenggunaan dana dan menyampaikan laporan pertanggungjawaban kepada Bupati/Walikota melalui DinasKebudayaan Kabupaten/Kota secara berkala.

Hal tersebut adalah sesuai dengan petunjuk teknis dalam pelaksanaan PestaKesenian Bali.

Sebagai seniman, Anak Agung Gde Rai sebagai pemiliki Museum ARMA (Agung Rai Musem of Art) di Ubud juga membagikan pengalaman suksesnya dalam Sarasehan Pesta Kesenian Bali ke-38 Tahun 2016 yang bertempat di ISI Denpasar. Beliaumen ceritakan mengenai kisah suksesnya dalam membangunrelasi/hubungan dengan berbagai pihak untuk mengenalkan budaya Bali ke dunia internasional. Sebagai narasumber dalam sarasehan tersebut, beliau memaparkan bahwa diperlukan 
kreativitas dan keberanian dari para seniman untuk memberikan nilai jual terhadap karya yang dihasilkannya. Dengan membangun hubungan dengan banyak pihak maka akan lebih besar kesempatan untuk memasarkan produk seni yang dihasilkan secara lebih luas danl ebih dikenal secara lebih lagi.

Antusiasme masyarakat Bali dalam menyaksikanpelaksanaan PKB sangatlah besar. Hal ini terlihat dari selalu ramainya pengunjung yang datang untuk menyaksikan berbagai pertunjukkan yang ditampilkandalam PKB. Hal tersebut dapat terlihat dari gambar berikut:

\section{Pengunjung dalam Pertunjukan PKB}

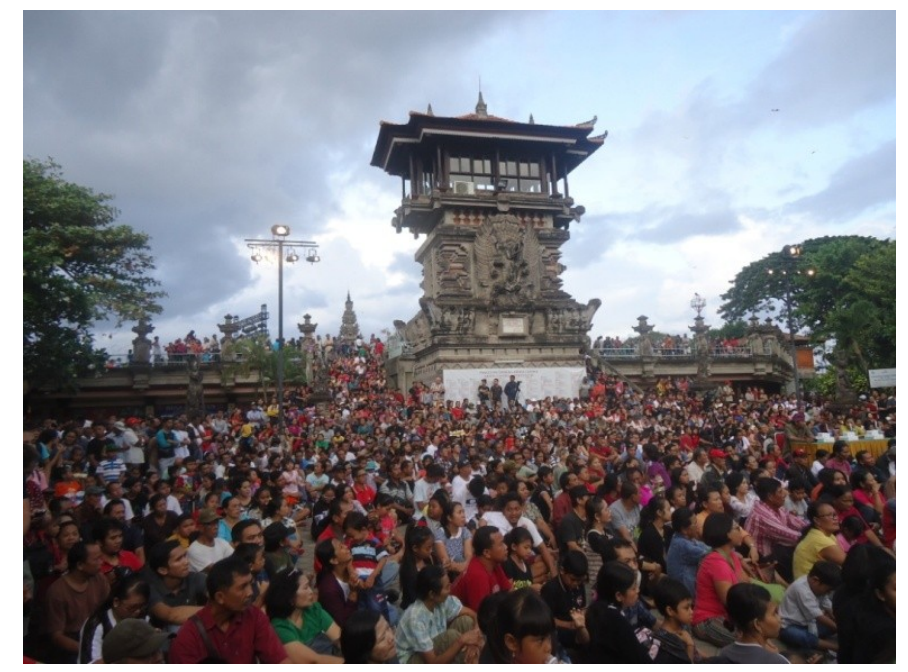

Sumber: DokumentasiPribadi

Dalam wawancara kepada 50 wisatawan mancanegara (wisman) pada saat PKB berlangsung, diketahui bahwa sumber informasi wisman untuk mengunjungi PKB (Satiadji, 2017) adalah seperti pada Tabel Media Promosi PKB ke-38 berikut: 


\section{Promotion Media}

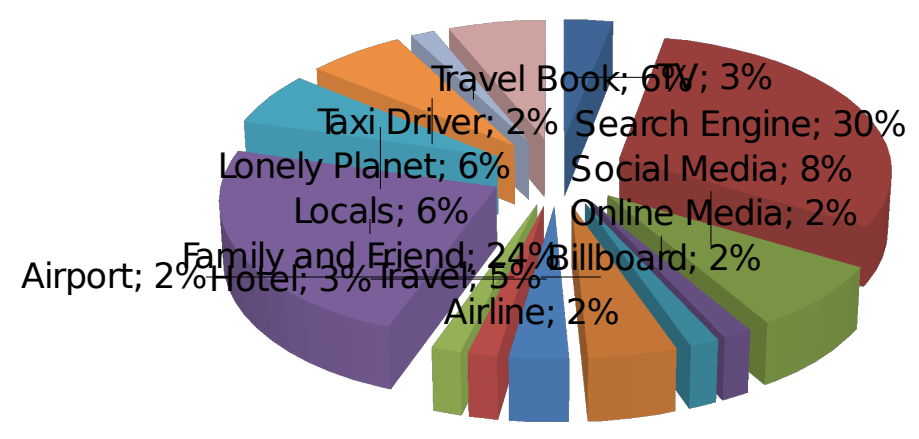

\section{Sumber: Data Diolah}

Pada Gambar tersebut diketahui bahwa sumber informasi wisman yang berkunjung ke Pesta Kesenian Bali ke-38, adalah sebesar 6\% wisman yang berkunjung mendapatkan informasi dari masyarakat Bali. Selain enam persen yang terlihat jelas, peran masyarakat Bali sebagian lagi terdapat dalam search engine 30\%, family and friend $24 \%$, dan media sosial $8 \%$ sebagai sumber wisman untuk datang dalam PKB.

I Nyoman Tirtayasa yang sedang menyaksikan lomba membaca cerpen (cerita pendek) saat penulis menjumpai dalam sebuah studio mini bertempat di area Gedung Ksirarnawa Taman Budaya Bali penulis bertemu dengan seorang. Setelah beberapa saat berbincang dengan diketahui bahwa tersebut merupakan orang tua dari salah seorang peserta, sekaligus merupakan Pembina bidang Nyastra di Kabupaten Badung, kemudian dilakukanlah wawancara secara lebih mendalam. Beliau memaparkan tentang peran orangtua dalam mendorong anak-anak sebagai generasi penerus untuk melestarikan kebudayaan Bali.

Tentunya kebudayaan Bali tidak semuanya disenangi atau digandrungi oleh anakanak dan remaja saat ini. Namun, merupakan peran dari orangtualah untuk memberikan dorongan kepada anak-anaknya untuk mau mempelajari, apabila diketahui ternyata anak tersebut memiliki bakat, tentunya akan mudah untuk mempelajari dan mengembangkannya. Tetap faktor dorongan orangtua pada saat awal untuk mencoba sangatlah penting artinya. Selain berbentuk dorongan secara arahan dan nasehat, diperlukan pula adanya dorongan financial dan waktu, yang tentunya memerlukan biaya untuk mengantar jemput yaitu transportasi, biaya latihan dan pembinaan, juga waktu untuk memperhatikan perkembangan anak-anak tersebut.

Dalam mengarahkan anak-anak untuk mempelajari budaya Bali, diharapkan tidak hanya kebudayaan yang popular saja yang dipelajari, namun juga yang bersifat sakral dan hampir punah. Disarankan beliau bahwa akan lebih menarik lagi apabila kesenian yang telah direkonstruksi kembali dalam PKB dapat dilombakan kepada anak-anak ataupun remaja sehingga kebudayaan tersebut akan lebih dikenal dan diharapkan akan semakin digemari. 
Peran orangtua dan anak-anak dalam pelestarian budaya juga tersirat melalui wawancara dengan Jero Mangku Darsana. Wawancara dilakukan dengan orang tua dari seniman dari sanggar Paripurna. Orang tua dari seniman itu bernama Bapak Jero Mangku Darsana bersama istrinya. Sebelum pertunjukan yang sangat spektakuler ditunjukkan oleh Tim Kesenian Duta Kabupaten Gianyar pada Pukul 18.50 wita, pada tanggal 6 Juli 2016, bertempat di pinggir sungai yang terdapat di Taman Budaya.Putra mereka menjadi Duta Kabupaten Gianyar untuk tampil di tingkat Provinsi yaitu dalam Pesta Kesenian Bali.

Sanggar Paripurna merupakan tempat dimana kedua orangtua ini mempercayakan putra mereka untuk belajar mengenai kesenian yang merupakan budaya tradisional Bali. Suatu hal yang mereka rasakan dengan keikutsertaan putra mereka dalam berkesenian adalah suatu kepribadian yang taat, santun, lembut, berprestasi, serta diharapkan dapat terhindar dari pergaulan remaja yang tidak baik yang sedang marak berkembang saat ini. Kontrol orang tua merupakan suatu hal penting yang harus selalu dilakukan untuk mengetahui kegiatan dan keberadaan para remaja yang merupakan putra-putri mereka.

Dengan mengikuti sanggar kesenian, putra mereka memiliki wadah dalam menyalurkan hobi yang dimiliki sekaligus dapat memiliki pergaulan yang baik, yang dicontohkan oleh pelatih mereka. Terdapat nilai-nilai yang selalu ditanamkan oleh pelatih I Made Sidia. Beliau meminta para anggotanya untuk hadir tepat waktu, sembahyang sebelum dan sesudah latihan, membuang sampah ditempatnya dan lain sebagainya.

Meskipun saat ini dalam berkesenian putra mereka telah mendapat kesempatan untuk mendapatkan penghasilan namun sebagai orangtua mereka tetap menekankan bahwa pendidikan formal di sekolah merupakan hal utama yang harus dijalankan sebaikbaiknya. Suatu hal yang penulis juga amati adalah saat Bapak Jero Mangku Darsana merekam pertunjukan yang dilakukan oleh Sanggar dimana putranya turut tampil di dalamnya. Beliau merekam pertunjukkan tersebut adalah selain sebagai dokumentasi kenangan bagi keluarga tersebut juga sekaligus dijadikan suatu bahan pembelajaran untuk menemukan kekurangan-kekurangan yang masih ada, yang tentunya dapat diperbaiki dan disempurnakan untuk penampilan yang lebih baik dikemudian hari. Sehingga dalam hal ini peran alat dokumentasi merupakan hal penting selain sebagai penyimpan Data juga sebagai bahan pembelajaran guna pertunjukkan uang lebih baik dikemudian hari.

Peran anak terlihat dari ketertarikan yang didukung dengan kemauan untuk berlatih. Dengan motivasi dari orangtua dan semangat dari anak-anak sehingga akhirnya timbul akan kecintaan pada budaya yang dimiliki melalui berkesenian. Dari wawancara tersebut dapat ditarik suatu kesimpulan yaitu dalam berkesenian, orangtua memegang peranan untuk memotivasi anak-anak mereka untuk mencintai budaya yang dimiliki, dengan perhatian penuh dalam aktifitas yang dilakukan, serta memberikan dukungan baik semangat (moril) dan materiil seperti pendanaan dan turut hadir bahkan merekam pertunjukan putra mereka untuk dapat menjadi dokumentasi pribadi. Agar budaya tetap dapat dilestarikan diperlukan kecintaan 
terhadap budaya tersebut. PKB merupakan wadah untuk mengapresiasi kecintaan dari orangtua dan anak-anak yang ada di Bali akan budaya Bali dengan memberikan sarana dan tempat untuk mengekspresikannya.

\section{Simpulan}

Adapun hasil yang diperoleh dari penelitian ini adalah sebagaiberikut: peran sebagai seniman, penonton, pemasar bagi event Pesta Kesenian Bali, sebagai orang tua yang mendukung dan mengarahkan anak-anaknya, serta perananak-anak yang mencintai budayanya sehingga dapat berlangsung secara turun-temurun.Peran ini sangatlah mendukung sebagai bentuk internal marketing di mana nilai-nilai budaya dapat diteruskan secara turun temurun dalam masyarakat melalui pelaksanaan event Pesta Kesenian Bali. Dengan pelaksanaan PKB yang diselenggarakan setiap tahun dan melibatkan seluruh kabupaten serta kota yang ada di Bali dimana sebagian besar masyarakat adalah pelaku pariwisata maka diharapkan nilai-nilai budaya yang benarakan tetap dianut dalam menjalankan kepariwisataan di Bali.

Diharapkan di dalam menjalankan pariwisata budaya, budaya merupakan paham yang harus dipegang. Dengan budaya, pelaku pariwisata, masyarakat, dan siapapun yang terlibat akan menjadi santun sepanjang budaya tersebut dimengerti, dihayati, dipahami, serta dilaksanakan sebagai implementasi dalam bentuk tindakan dan karya. Diharapkan dalammemasarkan pariwisata budaya, para pemangku kepentingan janganlah kapitalis hanya memandang nilai ekonomi yang ada, namun sesuai dengan budaya dan norma-norma aturan yang berlaku.

\section{Daftar Pustaka}

Kartajaya, Hermawan. 2010. Perjalanan Pemikiran Konsep Pemasaran. Surabaya: Erlangga

Kotler, Philip \&Keller, Kevin Lane. 2009.Manajemen Pemasaran Jilid 1\& 2. Jakarta: Erlangga

Preston, C.A. 2012. Event Marketing.Canada: Wiley

Satiadji, Amirosa R. 2017. Pemasaran Pariwisata Budaya Berbasis Pelestarian Budaya dalam Pesta Kesenian Bali. Bandung: Universitas Padjadjaran. 